\title{
Quiste triquilemal proliferante
}

\section{Proliferating trichilemmal cyst}

\author{
Paloma María Civetta ${ }^{1}$, Karina Latorre ${ }^{2}$, Mariana Hurtado $^{3}$ y Natalia Blaglieri ${ }^{4}$
}

\begin{tabular}{|c|c|}
\hline RESUMEN & \\
\hline $\begin{array}{l}\text { El quiste triquilemal proliferante es una entidad infrecuente que suele } \\
\text { afectar el cuero cabelludo de mujeres mayores de } 50 \text { años como un } \\
\text { tumor de lento crecimiento y que puede evolucionar a una transfor- } \\
\text { mación maligna (quiste triquilemal proliferante maligno). A conti- } \\
\text { nuación, se expone el caso de una paciente con una lesión en el cuero } \\
\text { cabelludo de gran tamaño, con diagnóstico histopatológico de quiste }\end{array}$ & $\begin{array}{l}\text { Palabras clave: quiste triquilemal proliferante, quiste triquilemal } \\
\text { proliferante maligno, tumor del cuero cabelludo. }\end{array}$ \\
\hline triquilemal proliferante. & Dermatol. Argent. 2020, 26 (2): 76-77 \\
\hline
\end{tabular}

\begin{abstract}
Proliferating trichilemmal cyst is an infrequent entity. It develops in the scalp of old women as a slow-growing tumoral lesion. In some cases, it evolves into a malignant transformation (malignant proliferating trichilemmal cyst). This paper reports the case of a woman with a large scalp lesion whose histopathological diagnosis is proliferating trichilemmal cyst.
\end{abstract}

Key words: proliferating trichilemmal cyst, malignant proliferating trichilemmal cyst, tumor in scalp.

Dermatol. Argent. 2020, 26 (2): 76-77

\footnotetext{
1 Médica Concurrente, Servicio de Dermatología

2 Médica de Planta, Servicio de Dermatología

3 Jefa, Servicio de Dermatología

${ }^{4}$ Médica de Planta, Servicio de Anatomía Patológica Servicio de Dermatología, Hospital Interzonal Rodolfo R. Rossi, La Plata, Provincia de Buenos Aires, Argentina
}

Contacto del autor: Paloma María Civetta

E-mail: palomacivetta@icloud.com

Fecha de trabajo recibido: 9/1/2020

Fecha de trabajo aceptado: 18/6/2020

Conflicto de interés: las autoras declaran que no existe conflicto de interés.

\section{CASO CLÍNICO}

Paciente de 80 años que consultó por una lesión asintomática, de 6 años de evolución. Se había iniciado como un pequeño tumor en la región frontal, que aumentó progresivamente de tamaño hasta producirle dificultad para peinarse y molestias estéticas.

En el examen físico presentaba, en la región frontal del cuero cabelludo, una tumoración exofítica, de $8 \times 6$ $\mathrm{cm}$, con áreas ulceradas y necróticas de consistencia duroelástica, sin adherencia a los planos profundos (Foto 1). No se palpaban adenopatías regionales.
Se realizó una biopsia con sacabocados, que informó la presencia de una proliferación lobulada del epitelio escamoso, con quistes centrales compuestos por queratina amorfa eosinofílica, sin capa granulosa interpuesta, queratinización individual y escasas mitosis típicas (Fotos 2 y 3 ). Con el diagnóstico de quiste triquilemal proliferante, se procedió a la extirpación total de la lesión mediante cirugía convencional, con márgenes de $1 \mathrm{~cm}$. El estudio histopatológico de la pieza quirúrgica no mostró focos de malignidad. La paciente concurrió a los controles pautados con buena evolución y no evidenció recidiva local. 


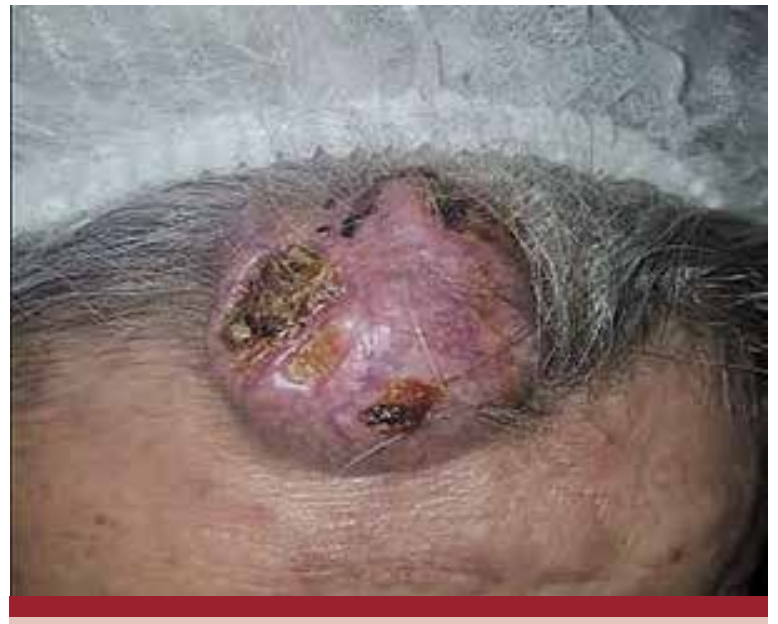

FOTO 1: Tumor en la región frontal del cuero cabelludo.

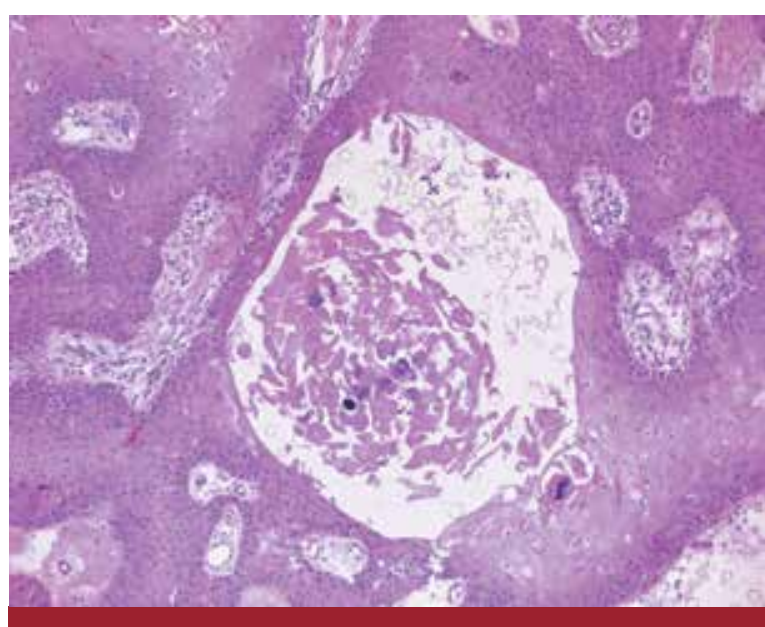

FOTO 2: Proliferación lobulada del epitelio escamoso con quistes centrales compuestos por queratina amorfa eosinofílica, sin capa granulosa interpuesta $(\mathrm{HyE}, 10 \mathrm{X})$.

\section{COMENTARIO}

El quiste triquilemal proliferante (QTP) es una neoplasia dérmica infrecuente que deriva de la vaina radicular externa del folículo piloso. En la mayoría de los casos, surge como complicación de un quiste triquilemal; menos a menudo, se origina de novo ${ }^{1}$.

Predomina en mujeres adultas y suele localizarse en el cuero cabelludo, aunque también puede originarse en otras regiones como pectoral, púbica o vulvar ${ }^{2,3}$.

Se presenta como un tumor exofítico, sólido o quístico, de lento crecimiento y con la superficie ulcerada ${ }^{1-4}$.

\section{BIBLIOGRAFÍA}

1. Romano MS, Ricaud ME, López S, Gallardo C. Quiste triquilemal proliferante atípico. Arch Argent Dermatol 2012;62:63-65.

2. Alam K, Gupta K, Maheshwari V, Varshney M. et ál. A large proliferating trichilemmal cyst masquerading as squamous cell carcinoma. Indian J Dermatol 2015;60:104.

3. Muñoz A, Lama F, Rueda X, Acosta A, et ál. Tumor pilar proliferante maligno en cuero cabelludo. Rev Colomb Cancerol 2013;17:119-121.

4. Valerio E, Parro FHS, Macedo MP de, Pinto CAL, et ál. Proliferating trichilemmal cyst with clinical, radiological, macroscopic, and

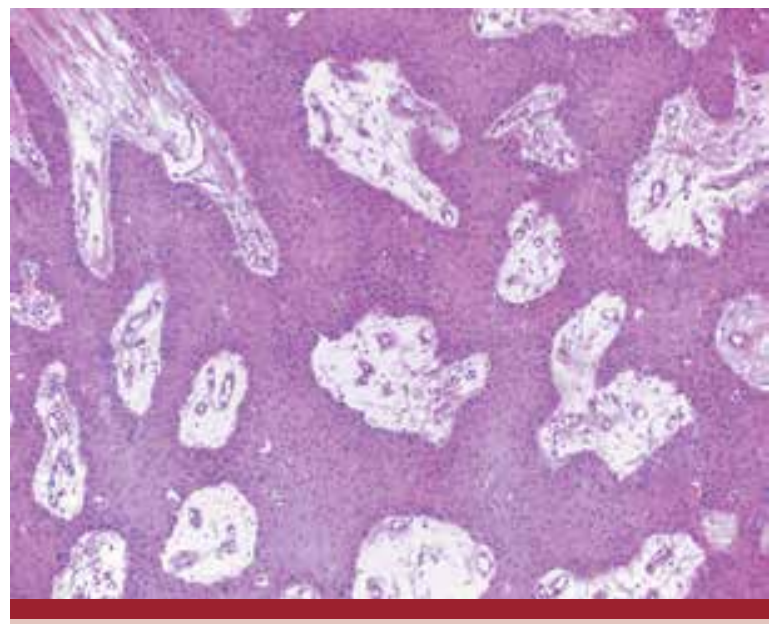

FOTO 3: Quiste con revestimiento epitelial carente de estrato granuloso con queratina en el centro de la lesión (HyE, 40X).

Su tamaño oscila entre 0,4 y $10 \mathrm{~cm}$ de diámetro 5

Los hallazgos histopatológicos evidencian una neoplasia sólida bien circunscripta en la dermis, que en algunos casos se extiende al tejido celular subcutáneo. El componente quístico presenta en las paredes una empalizada periférica, con células basaloides, que se diferencian a queratinocitos grandes con citoplasma eosinófilo y queratinización abrupta, sin capa granulosa ${ }^{6}$.

Puede ocurrir la transformación de un QTP en un QTP maligno, el cual presentará atipia citológica, pleomorfismo celular con mitosis atípicas, células disqueratósicas e infiltración de los márgenes adyacentes ${ }^{4}$.

Desde el punto de vista clínico, debe diferenciarse del quiste triquilemal, quiste sebáceo, hidradenomas de células claras, metástasis cutáneas, carcinoma espinocelular y angiosarcoma. Histológicamente, sus principales diagnósticos diferenciales se plantean con el carcinoma espinocelular y el QTP maligno ${ }^{1-3}$.

El tratamiento de elección es la extirpación quirúrgica $^{7}$. Si bien no hay un estándar definido en cuanto al margen oncológico, existe consenso en considerar la escisión local amplia con margen de $1 \mathrm{~cm}$ como la terapéutica adecuada ${ }^{4}$. En el caso del QTP maligno, el tratamiento es la extirpación con un margen oncológico mayor de $1 \mathrm{~cm}$, la terapia adyuvante y la radioterapia, a fin de evitar las recidivas?.

microscopic correlation. An Bras Dermatol 2019; 94:452-454.

5. Sethi S, Singh UR. Proliferating trichilemmal cyst: report of two cases, one benign and the other malignant. J Dermatol 2002;29:214-220.

6. Requena L, Crowason AN, Kaddu S, Kazakov DV, et ál. Proliferating Trichilemmal tumour. En: Elder DE, Massi D, Scolyer RA, Willemze R. WHO cassification of skin tumours. IARC, Lyon France, 2017;195-196.

7. Kim UG, Kook DB, Kim TH, Kim CH. Trichilemmal carcinoma from proliferating trichilemmal cyst on the posterior neck. Arch Craniofac Surg 2017;18:50-53. 